\title{
PROCESSO DE INDUSTRIALIZACCÃO DE LIGHT STEEL FRAME UTILIZANDO SISTEMAS DE SIMULAÇÃO COMO FACILITADORES NO CONTROLE DE MATERIAIS DE OBRA
}

\author{
Henrique P. Abad*, Patricia S. P. Fontanini.
}

\section{Resumo}

O Light Steel Frame (LSF) é sistema estrutural formado de perfis de aço galvanizado que são complementados por outros elementos (chapas, painéis, instalações elétricas e etc). Quando comparado aos sistemas tradicionais, é mais prático e racional, proporcionando ganhos na velocidade de execução e menor consumo de materiais. Do levantamento de dados acerca dessa tecnologia, tanto nacionalmente quanto internacionalmente, obteve-se treze artigos para serem analisados por completo após a realização do Mapeamento Sistemático da Literatura, sendo que as buscas retornaram 563 artigos inicialmente. Destes, apenas dez foram classificados como aderentes ao tema deste estudo por abordaram com riqueza de detalhes critérios técnicos de concepção de projeto, ferramentas e ponderações auxiliares à etapa de projetos e estudos de caso. Pesquisas complementares sobre projetos e o cenário do mercado nacional também foram realizadas na ABNT, na ABCEM, no PBQP-H e no CBCA. Esses materiais permitiram constatar a ausência de normas técnicas sobre o Light Steel Frame e a pequena quantidade de trabalhos que englobam estudos de caso. São disponibilizados vários manuais e diretrizes, listados neste estudo, que englobam algumas normas técnicas. $\mathrm{O}$ outro desafio para o crescimento desta tecnologia está associado à baixa quantidade de empresas que fabricam perfis de aço galvanizado e que se encontram centralizadas em determinados locais, como o estado de São Paulo..

\section{Palavras-chave:}

Light Steel Frame no Brasil, projetos, estudos de caso.

\section{Introdução}

O Light Steel Frame (LSF) é sistema estrutural formado de perfis de aço galvanizado projetados para aguentarem as cargas da edificação, dispensando o uso de vigas e pilares. Segundo Hass e Martins (2011), outros componentes, como painéis (para fechamento das faces das paredes), instalações hidráulicas e elétricas, elementos térmicos e acústicos, e demais, integram-se a essa tecnologia.

Apesar do crescente número de pesquisas sobre o tema, os dados estão dispersos, ressaltando-se a importância de organizá-los e unificá-los por meio de uma revisão sistemática. Esta pesquisa, assim, será voltada para essa lacuna, na parte de projetos e normas.

\section{Resultados e Discussão}

Do Mapeamento Sistemático da Literatura, obteve-se 563 artigos inicialmente. Após a remoção de duplicados, os artigos foram escolhidos de acordo com a relevância do título e posteriormente de acordo com o resumo, resultando em treze trabalhos de interesse, conforme a Figura 1.

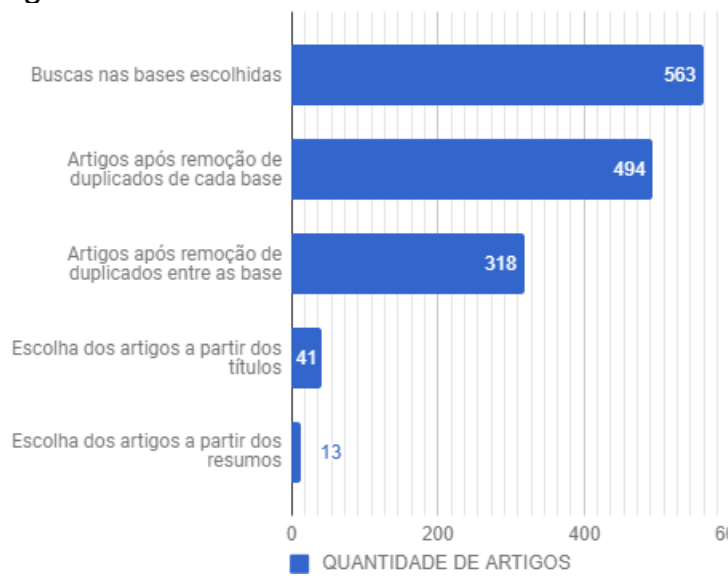

Figura 1. Filtros aplicados para seleção de artigos.
A segunda etapa, a Revisão Sistemática da Literatura, consistiu na leitura integral dos materiais escolhidos e nova classificação. As pesquisas abordaram normas relevantes internacionais, as melhorias sugeridas ao LSF, normas e diretrizes utilizadas em projetos brasileiros, ferramentais auxiliares de projetos e estudos de caso. Assim, dez trabalhos foram considerados como aderentes. Buscas na ABNT, na ABCEM, no PBQP-H e no CBCA também reforçaram o conteúdo desta etapa e da seguinte

Para a última etapa, a partir dos relatórios divulgados pelo CBCA e pela ABCEM entre 2014 e 2017, contatouse que o número de empresas voltadas ao LSF pouco alterou, a maior parte delas está no Sudeste do país (principalmente em São Paulo) e que elas operam abaixo da capacidade máxima disponível em pelo menos $50 \%$.

\section{Conclusões}

O Brasil ainda carece de uma norma técnica específica ao LSF. Os projetos atuais se baseiam em um conjunto de diversas outras normas e diretrizes, nacionais e internacionais.

As pesquisas sobre o LSF também pouco exploram os estudos de caso. Três dos dez artigos abordavam o assunto e apenas um deles é brasileiro. Essas análises são importantes para unir a teoria e a prática.

Por fim, o cenário da indústria de perfis de aço galvanizado no Brasil mostra outro desafio para esta tecnologia: descentralizar os pontos de fabricação. E potencial para crescimento existe, já que as empresas operam muito abaixo do limite.

\section{Agradecimentos}

À minha orientadora, Patricia, por todo apoio a este estudo desde o início do projeto, e ao $\mathrm{CNPq}$, pelo financiamento. 